\title{
Comprehensive Weighted Risk Assessment Based on GIS and SWMM in Chengdu, China
}

\author{
Xuejin YING, Ting $\mathrm{NI}^{1}$ and MingXia LU \\ College of Environment and Civil Engineering, Chengdu \\ University of Technology, China
}

\begin{abstract}
Comprehensive risk assessment of urban flooding disaster provides an effective way to reduce social losses and improve emergency management decisions for cities in China. Chengdu has suffered from frequent flooding disasters in recent years. In this paper, a risk assessment system was established for Jinjiang District of Chengdu City based on numerical model, a basic model was established by GIS. Runoff coefficient method was used to test the accuracy of the model. SWMM was used to simulate the rainfall event in order to obtain risk assessment indicators. According to the assessment results, the 224 areas are divided into 5 risk levels, including 105 higher-risk areas and 33 high-risk areas. Generally, the study area is still at high risk, and the local drainage system needs to be improved.
\end{abstract}

Keywords. Risk assessment, urban flooding modeling, GIS and SWMM, comprehensive weighted method.

\section{Introduction}

$<$ China agenda 21 $>$ [1] points out that in recent years, due to the rapid development of cities, the urban heat island effect has increased the frequency and intensity of heavy rainfall, and the urban drainage system is not perfect enough. The resulting urban flooding disaster began to occur frequently throughout the country. The successive internal flooding disasters in China have undoubtedly caused huge loss of life and property to Chinese residents. Therefore, urban flood disaster has become one of the key research directions in China. According to the Ministry of Housing and Urban and Rural Development Survey data on urban flooding disasters in 31 provinces and 351 cities across the country in 2010 [2], In just three years (2008-2010), $62 \%$ or $40 \%$ of the total flooding occurred in cities with three times of flooding. In terms of water depth, the depth of water in 262 cities is more than or equal to half a meter $(50 \mathrm{~mm})$. In terms of duration, $57 \%$ of cities last between 8 and 12 hours, the depth of water is as deep as $4 \mathrm{~m}$, and some roads traffic is completely paralyzed. However, floods are inevitable in most cities, therefore, it is important for those cities to evaluate the value of risk in urban flooding areas.

The methods commonly used before identification and assessment of flooding wind

\footnotetext{
${ }^{1}$ Corresponding Author, Ting NI, College of Environment and Civil Engineering, Chengdu University of Technology, China; Email: niting17@edut.edu.cn.
} 
risk include historical disaster mathematical statistics method, index system method and scenario-based simulation assessment method [3]. Geographic information systems (GIS) can be used to capture, store, manipulate, analyze, manage, and present spatial or geographic data [4]. Therefore, GIS is considered to provide relevant data (such as slope) for subsequent simulation and to build a flooding risk distribution map. In terms of model development, hydrodynamic models developed by scientific research institutions and companies in European and American developed countries are relatively mature. EPASWMM (Storm Water Management Model) is one of them. EPA-SWMM is a dynamic rainfall-runoff model used to simulate runoff and quality in major urban areas for single or continuous events [5]. The result report of the model simulation can give some data, such as the maximum overflow time of the sub-catchment area, the maximum water depth and the runoff coefficient.

Flood risk assessment is a complex systematic process, and the risk is caused by the joint action of disaster-causing factors (heavy rainfall intensity) and disaster-infecting factors (the main factors affecting drainage) under certain conditions. The weighted comprehensive evaluation method considers the flooding risk as a function of the interaction between the disaster-causing factor (D) and the disaster-infecting environment (S) [6]. Based on model simulation, four catastrophability indicators were selected in this paper, such as the maximum overflow time, the maximum water depth, the runoff coefficient and the maximum inundated area. And three sensitivity indicators have been chosen, such as roof, road and greening.

The purpose of this paper is to propose some risk indicators based on SWMM simulation and sensitivity indicators based on land use to assess the flooding risk in the study area and to classify the risk level according to the risk index. To achieve this goal, the data processing using GIS and SWMM is presented in Sect.3. Risk assessment system are presented in Sect. 4 and finally conclusion is given in Sect.5.

\section{Materials}

\subsection{Study Area}

Chengdu is located in southwest China and the western part of the Sichuan Basin, with flat terrain and a network of rivers. Jinjiang District of Chengdu is characterized by low topography, many rivers, complex water system, narrow downstream outlet section, poor urban drainage conditions. The annual rainfall in this area is about $854 \mathrm{~mm}$. Extremely rainfall events often occur in the summer. According to historical data and survey data, more than 80 percent of the study area is impervious, and most parts of the city experienced intense flooding. Therefore, this paper selected Jinjiang District as the study area. Figure 1 shows the geographical situation of the study area.

\subsection{Data}

The data used in this article is divided into three parts. The first part corresponds to the basic data of urban flood model, including digital elevation model (DEM), river data, drainage data and rainfall data. The second part includes observations of historical storm events used to calibrate urban inundation models. The third part is the flood risk assessment index, including the maximum overflow time, the maximum water depth, the 
runoff coefficient, the maximum smoke inundation area and the land use type. The above data are described in detail below.

DEM, river data and drainage data are derived from Geospatial Data Cloud

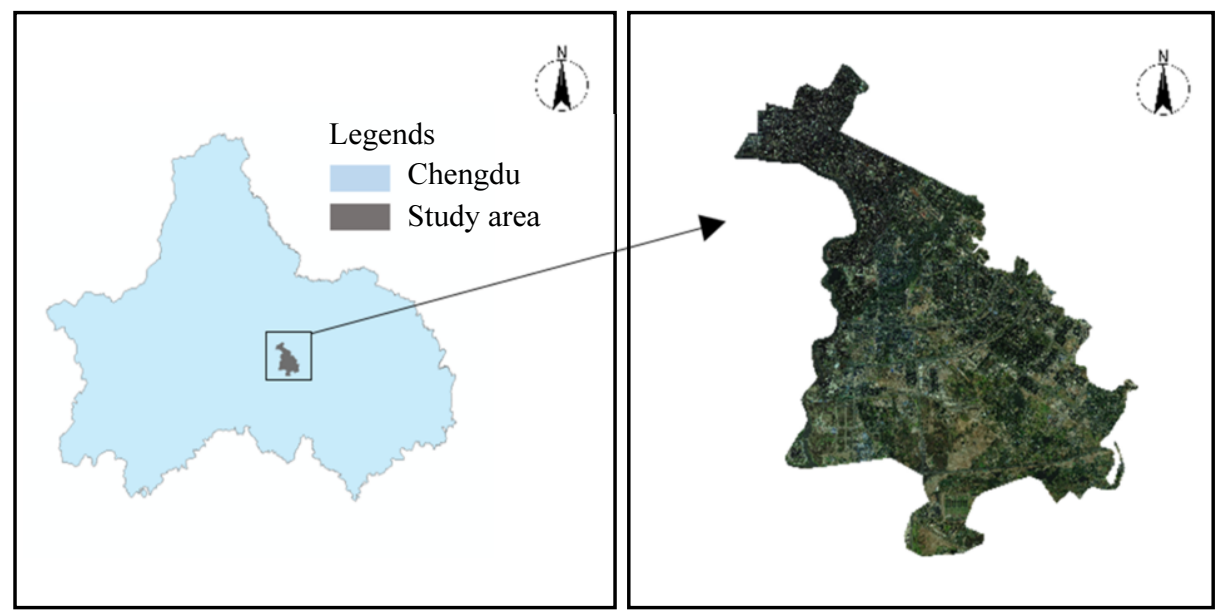

Figure 1. Study area of city of Chengdu

(http://www.gscloud.cn). The topographical condition of the study area can be reflected by the DEM. It can be used as the basic data of urban flood inundation model. On August 12, 2020, a heavy rainstorm occurred in Chengdu, and Jinjiang District was the worst hit, flooding 365 roads and paralysing traffic for nearly 12 hours, so choose this as the rainfall event in this study. The rainfall was provided by the Huizu Environment Platform of Langfang Smart Environment and Ecological Industry Research Institute (https://airwise.zc12369.com). The second and third of the data is from the model output.

\section{Modeling Process}

\subsection{Sub-Catchments}

Sub-catchment area refers to the catchment range of catchment point. Molecular catchment area refers to the reasonable distribution of surface runoff to the nodes of drainage pipe network to obtain the actual catchment situation. Hydrological analysis is the first step to construct the basic model of GIS. Because the study area is a high-density urban area, the Watershed tool in Hydrology cannot be used. In this study, the Tyson polygon method was used to divide the study area into 224 areas. Snap pourpoint tool in GIS can be used to obtain a drainage outlet corresponding to each area, so, it has 224. The basic model is shown in figure 2 . 


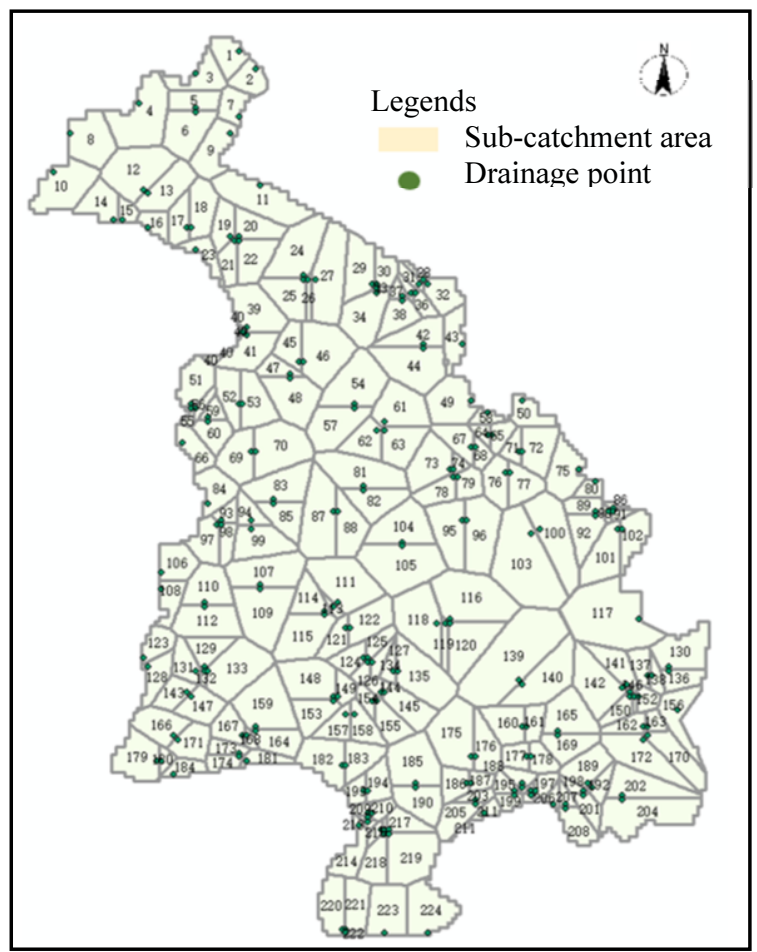

Figure 2. Tyson polygon-based catchment map

\subsection{Parameters}

The model parameters are divided into measurement parameters and calibration parameters, among which the measurement parameters are mainly calculated by GIS, while the calibration parameters are selected according to the actual local conditions.

The measurement parameters include the area, impervious ratio and slope of each sub-catchment. The area of each sub-catchment can be calculated by using the zonal geometric statistics tool in GIS, and the maximum area was 323 ha and the minimum area was 3 ha. The impervious ratio and average slope of each sub-catchment can be obtained through the spatial analysis tool in ArcGIS. Figure 3 and table 1 are the land use map and the measurement parameters of some sub-catchments respectively.

Table 1. Measurement parameters of some sub-catchments

\begin{tabular}{c|c|c|c|c}
\hline Sub-ID & Area / ha & Width / m & \% Slop & \% Impervious \\
\hline SUB1 & 14 & 374 & 3.0 & 74.8 \\
\hline SUB2 & 7 & 265 & 3.3 & 70.5 \\
\hline SUB3 & 2 & 141 & 4.5 & 98.7 \\
\hline SUB4 & 26 & 510 & 6.3 & 94.8 \\
\hline SUB5 & 29 & 539 & 4.6 & 92.1 \\
\hline SUB6 & 13 & 361 & 6.6 & 95.5 \\
\hline SUB7 & 4 & 200 & 6.5 & 91 \\
\hline
\end{tabular}

The calibration parameters include the width of each sub-catchment, Manning's N for overland flow for previous and impervious areas, depth of depression storage for impervious and previous, and percent of the impervious area with no depression. As the 
length of the ground flow is difficult to determine accurately, the square root of the area of the sub-catchment is used to determine the width of the sub-catchment, assuming that each sub-catchment is a square region. Since the simulated area belongs to a small watershed, Horton model was selected as the infiltration model, Dynamic Wave was selected as the confluence model, and relevant parameters were selected by referring to SWMM user manual [7-11]. The other parameters was selected based on the local actual situation, as shown in the table 2.

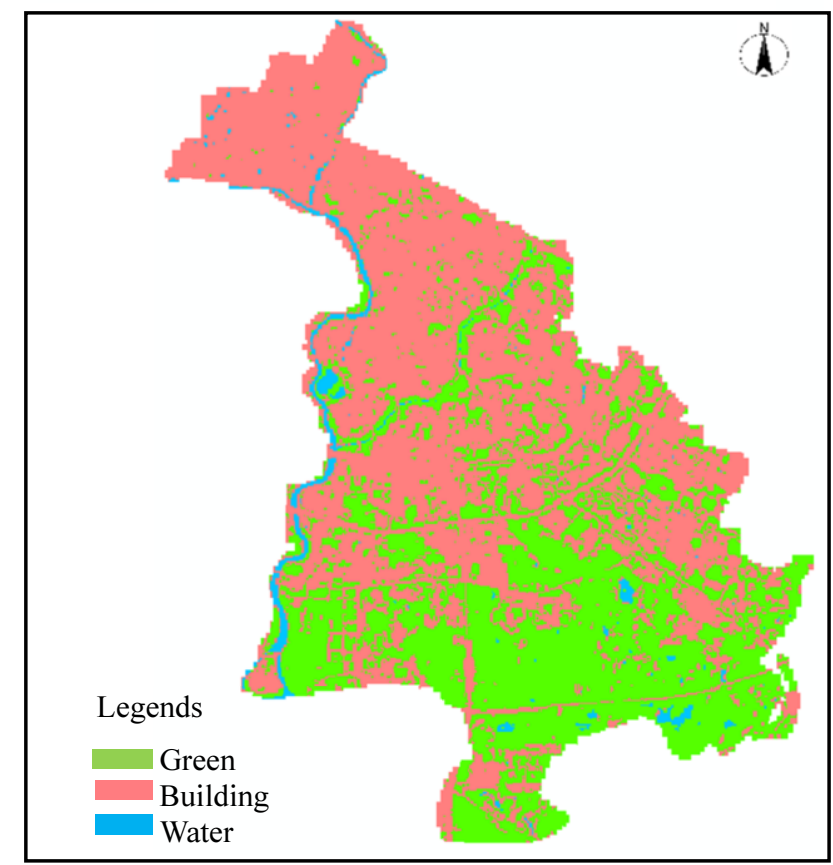

Figure 3. Impervious classification map of the study area.

Table 2. Model related parameter table.

\begin{tabular}{c|c}
\hline Parameter & Value \\
\hline N-Imperv & 0.011 \\
\hline N-Perv & 0.15 \\
\hline Dstore-Imperv & 0.06 \\
\hline Dstore-Perv & 0.15 \\
\hline \% Zero-Imperv & $35 \%$ \\
\hline Max. Infil. Rate & $5 \mathrm{in} / \mathrm{hr}$ \\
\hline Min. Infil. Rate & $4.74 \mathrm{in} / \mathrm{hr}$ \\
\hline Decay Const & 4 \\
\hline
\end{tabular}

\subsection{Model Calibration}

In order to ensure the reliability and accuracy of the model, it is necessary to verify the constructed model. As part of the pipeline network in the study area is still under planning and lacks the measured pipeline flow data, the comprehensive runoff coefficient method is adopted to verify the model accuracy to ensure the authenticity and reliability of the simulation results.

The principle of the comprehensive runoff coefficient method is to compare the 
runoff coefficient obtained by model simulation with the comprehensive runoff coefficient of catchment area to see whether the result is within the value range. The comprehensive runoff coefficient is calculated according to GB 50014 -- 2006 Code for Design of Outdoor Drainage [12], as shown in table 3.

Table 3. Table of runoff coefficient of catchment area.

\begin{tabular}{c|c|c}
\hline Area & Impervious rate / \% & Runoff coefficient \\
\hline Built-up area & $>70$ & $0.6 \sim 0.8$ \\
\hline More densely area & $50 \sim 70$ & $0.5 \sim 0.7$ \\
\hline Less built-up area & $30 \sim 50$ & $0.4 \sim 0.6$ \\
\hline Sparsely built area & $<30$ & $0.3 \sim 0.5$ \\
\hline
\end{tabular}

According to the impervious rate of each region calculated by GIS, the average impervious rate of the research region is $56.2 \%$. As shown in table 3 , the study area belongs to more densely area. In this study, the runoff coefficients of the rainfall event simulation are 0.67 , which meet the more densely area runoff coefficient range. Therefore, the model is considered to have certain reliability.

\subsection{Swmm Simulation Results}

The inundation situation will be shown in the SWMM report, including inundated nodes, the maximum water depth and maximum overflow time, etc. Table 4 shows the runoff information.

Table 4. The runoff information.

\begin{tabular}{c|c|c|c|c|c}
\hline Rainfall event & $\begin{array}{c}\text { Number of } \\
\text { inundated } \\
\text { nodes }\end{array}$ & $\begin{array}{c}\text { Maximum } \\
\text { water depth }\end{array}$ & $\begin{array}{c}\text { Maximum } \\
\text { overflow rate }\end{array}$ & $\begin{array}{c}\text { Maximum } \\
\text { overflow } \\
\text { time }\end{array}$ & $\begin{array}{c}\text { Maximum } \\
\text { overflow } \\
\text { volume }\end{array}$ \\
\hline $\begin{array}{c}\text { August 12, 2020 (12 } \\
\text { a.m. to 4 p.m) }\end{array}$ & 180 & $350 \mathrm{~mm}$ & $1.35 \mathrm{~m}^{3} / \mathrm{s}$ & $5.8 \mathrm{~h}$ & $11528 \mathrm{~m}^{3}$ \\
\hline
\end{tabular}

\section{Risk Assessment System}

Flooding disaster is considered as a function between the hazard factor (C) and the sensitivity of the carrier (S), as shown in Formula 1.

$$
\mathrm{R}=W_{D_{i}} \sum_{k}^{n} C_{i k} W_{i k}+W_{S_{i}} \sum_{j}^{m} S_{i j} W_{i j}
$$

where $\mathrm{i}$ is the sub-catchment; $\mathrm{W}_{\mathrm{Di}}$ and $\mathrm{W}_{\mathrm{Si}}$ respectively represent the weight of catastrophability and sensitivity; $\mathrm{C}_{\mathrm{ik}}$ represent the score of the kth catastrophability factor; $\mathrm{S}_{\mathrm{ij}}$ represent the score of the jth sensitivity factor; $\mathrm{W}_{\mathrm{ik}}$ represent the weight of the kth catastrophability factor; $\mathrm{W}_{\mathrm{ij}}$ represent the weight of the jth sensitivity factor. Table 4 shows the risk assessment system of flooding catastrophability and sensitivity in Jinjiang District. 
Table 4. The risk assessment system of flooding catastrophability and sensitivity in Jinjiang District.

\begin{tabular}{|c|c|c|c|c|}
\hline Index & Factor & Standard & Score & Weight \\
\hline \multirow{16}{*}{$\begin{array}{c}\text { Catastrophability } \\
(0.6)\end{array}$} & \multirow{4}{*}{ Maximum overflow time } & $<3 \mathrm{~h}$ & 1 & \multirow{4}{*}{0.3} \\
\hline & & $3 \sim 6 \mathrm{~h}$ & 2 & \\
\hline & & $6 \sim 9 \mathrm{~h}$ & 3 & \\
\hline & & $>9 \mathrm{~h}$ & 4 & \\
\hline & \multirow{4}{*}{ Maximum water depth } & $<0.1 \mathrm{~m}$ & 1 & \multirow{4}{*}{0.2} \\
\hline & & $0.1 \sim 0.4 \mathrm{~m}$ & 2 & \\
\hline & & $0.4 \sim 0.8 \mathrm{~m}$ & 3 & \\
\hline & & $>0.8 \mathrm{~m}$ & 4 & \\
\hline & \multirow{4}{*}{ The runoff coefficient } & $<0.4$ & 1 & \multirow{4}{*}{0.3} \\
\hline & & $0.4 \sim 0.6$ & 2 & \\
\hline & & $0.6 \sim 0.9$ & 3 & \\
\hline & & $>0.9$ & 4 & \\
\hline & \multirow{4}{*}{ Maximum submerged area } & $<10$ ha & 1 & \multirow{4}{*}{0.2} \\
\hline & & $10 \sim 60$ ha & 2 & \\
\hline & & $60 \sim 100$ ha & 3 & \\
\hline & & $>100$ ha & 4 & \\
\hline \multirow{12}{*}{ Sensitivity $(0.4)$} & \multirow{4}{*}{ Roof (residential or business) } & $<10 \%$ & 1 & \multirow{4}{*}{0.6} \\
\hline & & $10 \% \sim 30 \%$ & 2 & \\
\hline & & $30 \% \sim 60 \%$ & 3 & \\
\hline & & $60 \% \sim 80 \%$ & 4 & \\
\hline & \multirow{4}{*}{ Road (main road or pavement) } & $<10 \%$ & 1 & \multirow{4}{*}{0.3} \\
\hline & & $10 \% \sim 20 \%$ & 2 & \\
\hline & & $20 \% \sim 30 \%$ & 3 & \\
\hline & & $30 \% \sim 40 \%$ & 4 & \\
\hline & \multirow{4}{*}{ Green (lawn) } & $<10 \%$ & 1 & \multirow{4}{*}{0.1} \\
\hline & & $10 \% \sim 30 \%$ & 2 & \\
\hline & & $30 \% \sim 60 \%$ & 3 & \\
\hline & & $60 \% \sim 80 \%$ & 4 & \\
\hline
\end{tabular}

\section{Result and Analysis}

The risk level of this rainfall event is divided into five levels according to the result of risk assessment system. 1-1.5 is low risk area, 1.5-2 is lower risk area, 2-2.4 is medium risk area, 2.4-3 is higher risk area, and greater than 3 is high risk area. There were 224 study areas in total, of which 39 were low risk areas, 30 lower risk areas, 17 medium risk areas, 105 higher risk areas and 33 high risk areas.

As shown in figure 4, high-risk areas are mainly concentrated in the northwest. The study area is mainly commercial and residential with almost no greening facilities. As this area is an old city, the city ranking system is relatively old. Due south of this area is a new area built later, which is characterized by abundant greening and advanced drainage facilities, so it is mainly a low-risk and lower-risk area.

\section{Conclusions}

The evaluation of drainage capacity and flooding risk could provide an example for better urban flood control and drainage planning and urban underground pipe network planning. There are three conclusions:

(1) Taking Jinjiang District of Chengdu City as the study area, hydrological analysis and sub-catchment division can be used in this paper combined with GIS spatial 
analysis tools, such as regional slope, impervious rate, regional area, etc. It also built a drainage model that is more consistent with the actual situation for the subsequent SWMM model.

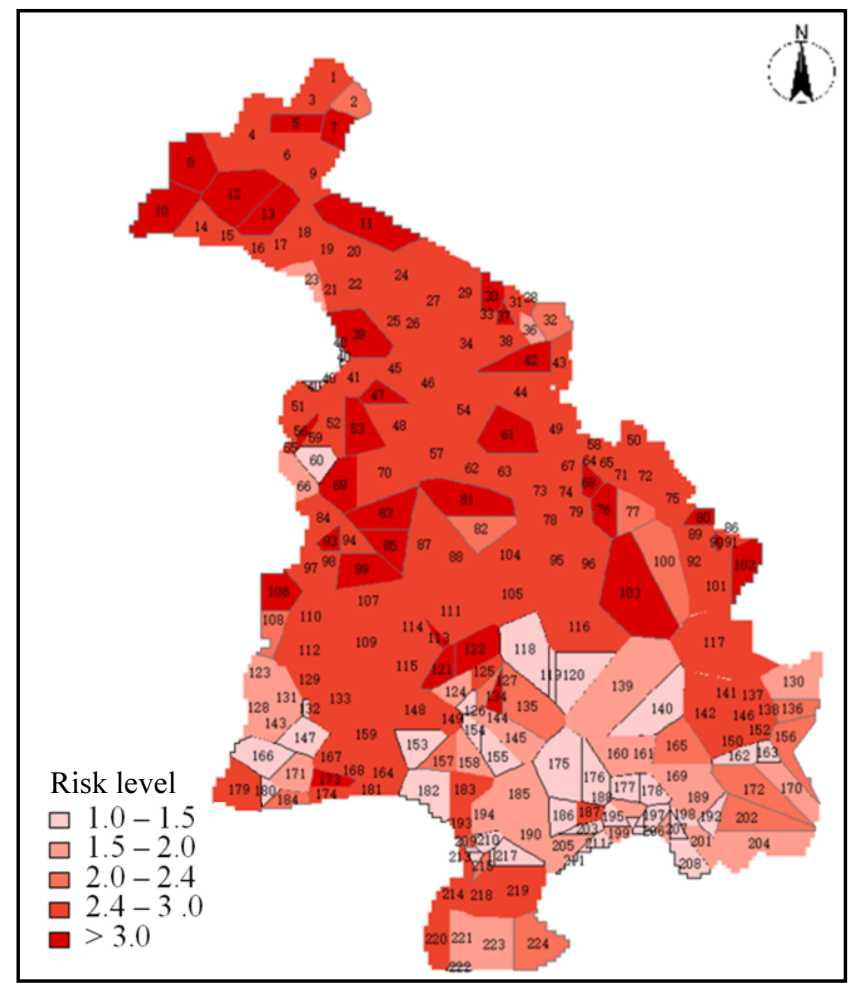

Figure 4. Flood risk map generated by the comprehensive weighted method

(2) GIS was used to process and extract the preliminary data of SWMM model construction, and the reliability of the model was verified by runoff coefficient method in the absence of measured data, and the verified model was used for case analysis of the study area. The results show that this method can process the preliminary data of model construction conveniently and effectively, simplify and sort out the complex data effectively, and is more accurate and efficient than manual statistics and input method.

(3) Based on an actual rainfall event (August 12, 2020), some flooding related data were obtained by input model. Based on this, the flooding risk assessment system was established, and the flood risk map was obtained by quantifying the risk value. The map shown in this study are consistent with DEM and land use map, indicating that the drainage model and evaluation system can well describe the actual flooding risk. 


\section{References}

[1] China Agenda 21 Management Center. Water Resources Management in China [M]. Beijing: Social Sciences Academic Press, 2010.

[2] He Fafa, Chen Xiaoli, Zhang Yajie, Fang Yuan.GIS-Assisted Risk Assessment of Waterlogging Disaster: A Case Study of Pao Xiedao Community. Surveying and Mapping Geographic Information.2015.40.3 4.

[3] Zhang Dongdong, Yan Denghua, Wang Yicheng, et al. Research progress on risk assessment and comprehensive response of urban waterlogging disaster [J]. Journal of Catastrophology, 2014, 29(001):144-149.

[4] National Bureau of Statistics, PRC. China Statistical Yearbook [M]. Beijing: China Statistical Press,2020.

[5] Pathirana A, Tsegaye S, Gersonius B et al (2008) A simple 2-D inundation model for incorporating flood damage in urban drainage planning. Hydrol Earth Syst Sci 5(6):30613097. https ://doi.org/10.5194/hess-15-2747-2011

[6] Dai Jingjing, Liu Zengxian, Lu Shenjun. Research on risk assessment of urban waterlogging based on numerical simulation [J]. Water Resources Planning and Design, 2015.

[7] Rossman L A. Storm water management model user's manual version 5.0 [M] Washington: National risk managementresearch laboratory, Office of research and development, U S En-vironmen - tal Protection Agency.

[8] McCuen R, Johnson P, Ragan R (1996) Highway hydrology. Hydraulic design series No. 2. U.S. Department of Transportation, Federal Highway Adminstration, Washington, D.C. pp 326.

[9] ASCE (1992) Design and construction of urban stormwater management systems, New York.

[10] ASCE (1982) Gravity sanitary sewer design and construction. ASCE manual of practice No. 60, New York.

[11] Rawls, W.J.et al.,(1983).J.Hyd.Engr.,109:1316.

[12] Shanghai Municipal Construction and Transportation Commission. Code for design of outdoor drainage. The fourth edition [M]. China Planning Publishing House, 2016. 